\title{
REVIEW ARTICLE \\ The pandemic potential of avian influenza A(H7N9) virus: a review
}

\author{
W. D. TANNER ${ }^{1}$, D. J. A. TOTH ${ }^{1,2}$, AND A. V. GUNDLAPALLI ${ }^{1,2 *}$ \\ ${ }^{1}$ Division of Epidemiology, Department of Internal Medicine, University of Utah, Salt Lake City, UT, USA \\ ${ }^{2}$ VA Salt Lake City Health Care System, Salt Lake City, UT, USA
}

Received 10 April 2015; Final revision 22 May 2015; Accepted 17 June 2015;

first published online 24 July 2015

\section{Summary}

In March 2013 the first cases of human avian influenza A(H7N9) were reported to the World Health Organization. Since that time, over 650 cases have been reported. Infections are associated with considerable morbidity and mortality, particularly within certain demographic groups. This rapid increase in cases over a brief time period is alarming and has raised concerns about the pandemic potential of the H7N9 virus. Three major factors influence the pandemic potential of an influenza virus: (1) its ability to cause human disease, (2) the immunity of the population to the virus, and (3) the transmission potential of the virus. This paper reviews what is currently known about each of these factors with respect to avian influenza A(H7N9). Currently, sustained human-to-human transmission of H7N9 has not been reported; however, population immunity to the virus is considered very low, and the virus has significant ability to cause human disease. Several statistical and geographical modelling studies have estimated and predicted the spread of the H7N9 virus in humans and avian species, and some have identified potential risk factors associated with disease transmission. Additionally, assessment tools have been developed to evaluate the pandemic potential of H7N9 and other influenza viruses. These tools could also hypothetically be used to monitor changes in the pandemic potential of a particular virus over time.

Key words: Avian flu, influenza, influenza A, pandemic, risk assessment.

\section{Search strategy}

Data for this review are from publications identified through a systematic search in the Scopus (Elsevier) publication database and PubMed using the key words 'H7N9' during any time period. The search returned over 700 articles. Abstracts of the papers written in English were reviewed for relevance, followed by an examination of the papers referenced in this review. In

\footnotetext{
* Author for correspondence: A. V. Gundlapalli, MD, PhD, MS, Immunology 5B114D SOM, University of Utah School of Medicine, Salt Lake City, UT 84132, USA.

(Email: Adi.Gundlapalli@hsc.utah.edu)
}

addition, relevant government and international organization websites [World Health Organization (WHO), U.S. Centers for Disease Control and Prevention, and the Hong Kong Center for Health Protection] were reviewed for pertinent information.

\section{Background and epidemiology}

The first reports of avian influenza A(H7N9) emerged from Eastern China in early 2013 [1, 2]. Prior to the emergence of H7N9 human cases, avian influenza A (H5N1), first reported in humans in 1997 [3], received a significant amount of attention as the next potential 
Table 1. Comparison of pathogen characteristics of the H7N9 and H5N1 avian influenza viruses

\begin{tabular}{|c|c|c|}
\hline Characteristic & $\mathrm{H} 7 \mathrm{~N} 9$ & $\mathrm{H} 5 \mathrm{~N} 1$ \\
\hline Pathogenicity & Low pathogenicity (LPAI) & Highly pathogenic (HPAI) \\
\hline Total number of cases* & $660[3]$ & $827[3]$ \\
\hline $\begin{array}{l}\text { First case detected in } \\
\text { humans }\end{array}$ & 2013 [3] & $1997[3]$ \\
\hline Case-fatality rate* & $39 \%[1]$ & $53 \cdot 2 \%[3]$ \\
\hline Incubation period & Median 2-7 days, range $1-10$ days $[5,6]$ & 2-4 days (up to 8 days) [4] \\
\hline $\begin{array}{l}\text { Epidemiological risk } \\
\text { factors }\end{array}$ & $\begin{array}{l}\text { Older adults; more common in males; } \\
\text { comorbidities: COPD, diabetes, hypertension, } \\
\text { obesity, chronic lung and heart disease [25] }\end{array}$ & Younger adults; more common in females [12] \\
\hline $\begin{array}{l}\text { Average age of } \\
\text { infected individuals }\end{array}$ & $\begin{array}{l}54-63 \text { years of age; cases in children, teenagers } \\
\text { and young adults are rare [25] }\end{array}$ & $20-30$ years of age $[12]$ \\
\hline Host tropism & Humans, chickens, pigeons, ducks, geese $[10,11]$ & $\begin{array}{l}\text { Humans, wild migratory birds (LPAI), ducks, } \\
\text { geese, chickens (HPAI) }[7,8]\end{array}$ \\
\hline Human tissue tropism & $\begin{array}{l}\text { Epithelial and endothelial cells of multiple organ } \\
\text { systems, particularly human bronchus and lung } \\
\text { epithelial cells }[10,11]\end{array}$ & $\begin{array}{l}\text { Epithelial and endothelial cells of multiple organ } \\
\text { systems, particularly human bronchus and lung } \\
\text { epithelial cells }[7,8]\end{array}$ \\
\hline $\begin{array}{l}\text { Geography of human } \\
\text { cases }\end{array}$ & $\begin{array}{l}\text { Mainland China, Imported cases in Canada, } \\
\text { Taiwan, Malaysia, and Hong Kong [3] }\end{array}$ & $\begin{array}{l}\text { Azerbaijan, Bangladesh, Cambodia, Canada, } \\
\text { China, Djibouti, Egypt, Indonesia, Iraq, Lao } \\
\text { People's Democratic Republic, Myanmar, } \\
\text { Nigeria, Pakistan, Thailand, Turkey, and } \\
\text { Vietnam [3] }\end{array}$ \\
\hline Vaccine status & $\begin{array}{l}\text { No vaccines yet; Eight candidate vaccine viruses } \\
\text { [27] }\end{array}$ & US FDA approved vaccine in 2013 [28] \\
\hline Treatments & Neuraminidase (NA) inhibitors [12] & Neuraminidase inhibitors [12] \\
\hline Antiviral resistance & $\begin{array}{l}\text { Most isolates sensitive to NA inhibitors } \\
\text { (oseltamivir, zanamivir); resistance to } \\
\text { adamantanes (amantadine and rimantadine) } \\
\text { [12] }\end{array}$ & $\begin{array}{l}\text { Most isolates sensitive to NA inhibitors } \\
\text { (oseltamivir, zanamivir); resistance to zanamivir } \\
\text { reported in some wild-type strains; resistance } \\
\text { to adamantanes (amantadine and rimantadine) } \\
{[12,13]}\end{array}$ \\
\hline $\begin{array}{l}\text { Reproductive number } \\
R_{0}\end{array}$ & $0 \cdot 08-0 \cdot 39[18,19]$ & $0 \cdot 1-0 \cdot 4[21]$ \\
\hline $\begin{array}{l}\text { Reservoir and } \\
\text { exposure risks }\end{array}$ & $\begin{array}{l}\text { Wild birds, domestic birds (poultry), poultry } \\
\text { markets, wet markets [14] }\end{array}$ & Wild birds, domestic birds (poultry) $[7,15]$ \\
\hline $\begin{array}{l}\text { Human to human } \\
\text { transmission }\end{array}$ & $\begin{array}{l}\text { Low to moderate transmissibility; some family } \\
\text { clusters reported; no sustained transmission }[12 \text {, } \\
18,19]\end{array}$ & $\begin{array}{l}\text { Low transmissibility; limited human-to-human } \\
\text { transmission has been reported }[12,21]\end{array}$ \\
\hline Population immunity & Low or non-existent $[22-24]$ & Low or non-existent $[22,24]$ \\
\hline
\end{tabular}

COPD, Chronic obstructive pulmonary disease.

*As of 11 May 2015.

pandemic pathogen. While there have been more $\mathrm{H} 5 \mathrm{~N} 1$ cases to date than $\mathrm{H} 7 \mathrm{~N} 9$ cases, these cases have been reported over an 18-year period [3]. By contrast, the H7N9 case count has risen to nearly $80 \%$ of the current $\mathrm{H} 5 \mathrm{~N} 1$ case count in only 2 years. The H7N9 and H5N1 viruses share many similar characteristics, including incubation time [4-6], host and human tissue tropism [7-11], treatments [12], antiviral sensitivity [12, 13], reservoirs [14-17], reproductive numbers [18-21], and low levels of population immunity to both viruses [22-24]. There are also some significant differences between the two viruses, including epidemiological risk factors $[4,12,25]$, case-fatality rates [1, 3], geography of human cases [3, 26], vaccine status [27, 28], and the degree of pathogenicity in humans and poultry $[9,29]$. Table 1 summarizes specific similarities and differences between the two viruses.

Outbreaks of the H7N9 virus generally follow a seasonal trend, with three major waves of outbreaks occurring to date (Fig. 1 [30]): one from approximately February to May 2013 followed by a larger outbreak from approximately November 2013 to May 2014 [30, 31]. In late 2014 and early 2015, case counts began to increase again, and as of early 2015 , another wave of H7N9 infections has occurred, with 200 cases being reported from mainland China since November 


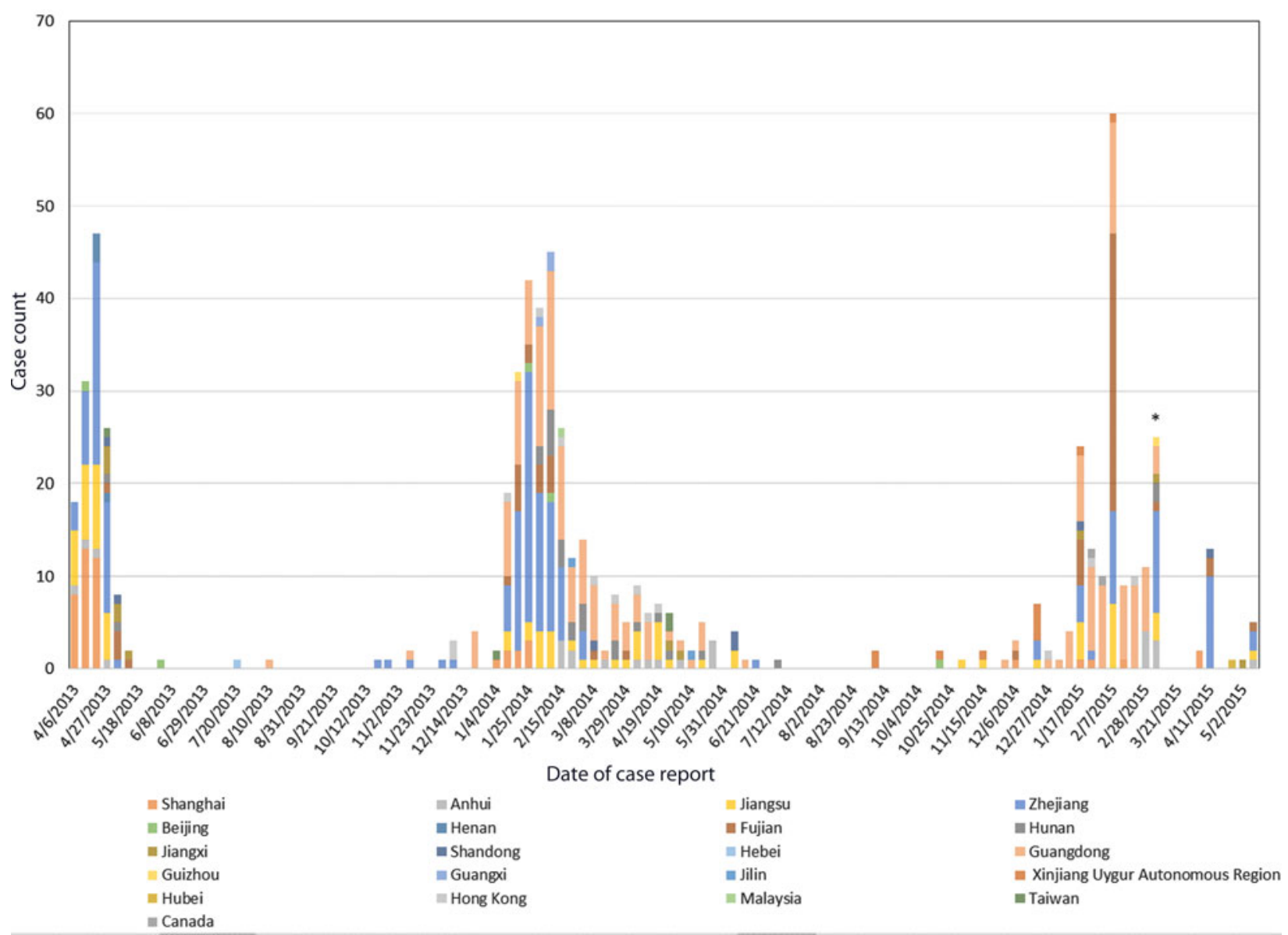

Fig. 1. Number of H7N9 cases reported weekly since April 2013; as of May 2015. Number of cases each week are based on dates of case reports from the Hong Kong Centre for Health Protection. Data source: Hong Kong Centre for Health Protection weekly Avian Influenza Report [32]. * Nineteen cases were reported on 10 March 2015, with onset dates in the 5 weeks preceding 25 February. These cases were added to others reported 10 March 2015, thus the distribution of H7N9 cases over this time period is slightly distorted.

2014, and 120 cases alone being reported from in the first 7 weeks of 2015 [3, 32, 33]. Divergence of the H7N9 virus into distinct clades between the first and second waves was reported, with co-circulation of multiple H7N9 clades during the second major wave [34]; however, one specific clade was responsible for most cases in the second wave, indicating widespread geographical dispersion. No significant difference in gender or age distribution was observed between the first and second waves. The geographical distribution of H7N9 cases shifted between the first and third waves. No cases were reported in Guangdong during the first wave of the outbreak, but this province had the highest number of reported cases during the third wave [3, 35]. Although increased heterogeneity of H7N9 virus gene sequences has been observed in the third wave, no major genetic changes in the virus have been documented [36]. Transmissibility of the virus does not appear to have increased in the third wave, and the majority of the most recent cases have been associated with contact with poultry or contaminated poultry environments [37].

Data on mild H7N9 infections is limited; however, reports indicate that mild disease is more frequently observed in paediatric patients. An investigation of cluster transmissions in Guangdong was conducted through follow-up of 3228 close contacts of known H7N9 cases. Of six identified cases, two adults developed severe infections. The remaining patients were paediatric cases that developed mild symptoms and fully recovered [38]. In 2013, a surveillance network tested over 20000 patients with influenza-like illness (ILI) for H7N9. Six patients were positive, four of whom were hospitalized. The ages of the hospitalized patients ranged from 25 to 69 years. Two paediatric cases, aged 2 and 4 years, were not hospitalized [39]. 
The median H7N9 incubation period is 2-7 days, with a range of $1-10$ days $[5,6]$. For cases that are ultimately fatal, the median time from onset of illness to death is $12-21$ days, with hospitalization typically occurring 4-5 days after onset [5]. Most reported cases of human H7N9 infection have exhibited severe respiratory illness [29]. Other common symptoms include fever, cough, and dyspnoea, and elevated levels of aspartate, aminotransferase, creatine kinase, lactate dehydrogenase [40]. Patients may develop severe complications, including acute respiratory distress syndrome, shock, congestive heart failure, myelitis, acute kidney injury, vomiting, diarrhoea, rhabdomyolysis, and multi-organ failure [5, 40].

Influenza $\mathrm{A}(\mathrm{H} 7 \mathrm{~N} 9)$ virus is associated with an agespecific and sex-specific morbidity and mortality [5]. The majority of the severe and fatal H7N9 cases have been in older adults with pre-existing conditions; cases in children, teenagers, and young adults are uncommon [5, 41]. Males are at a higher risk of infection, with approximately $70 \%$ of the reported cases in males [42]. The reported median age of confirmed cases ranges from to 54 to 63 years [43, 44]. Severe disease and fatal cases have occurred more frequently in middle-aged and older men compared to women [5, 41]. The most severe H7N9 infections appear to be associated with other comorbidities [45]. Underlying conditions associated with H7N9 cases include chronic obstructive pulmonary disease, diabetes, hypertension, obesity, chronic lung and heart disease [46]. Pregnancy is typically considered a risk factor for influenza-associated morbidity and mortality [47], which is consistent with two case reports of H7N9 infections in pregnant women. One case reported fetal death resulting from severe refractory hypoxemia, followed by the death of the mother due to infection-related complications [48]. Another case report describes the full recovery of a pregnant woman with no long-term adverse effects on the fetus as a result of the infection [49, 50]; although reports suggest that the woman was more susceptible to the H7N9 virus, based on her exposure patterns compared to those of family members [50].

\section{Disease management strategies}

Antiviral treatment is associated with improved outcomes and decreased viral load in patients with H7N9 infections [51, 52]. Late initiation of antiviral therapy is associated with an increased risk of death [53]. Laboratory studies in China have indicated that
H7N9 viruses are sensitive to neuraminidase inhibitor antiviral drugs such as oseltamivir and zanamivir [29]; however, they are resistant to adamantanes (amantadine and rimantadine), so these antivirals are not recommended for treating H7N9 [54]. Some studies have reported strains of the H7N9 virus that are resistant to oseltamivir and other neuraminidase inhibitor drugs [55-57]. Experimental antiviral treatments are also currently being explored [58, 59]. In addition to treatment with antivirals, supportive therapy may be instituted, and is particularly critical in cases of respiratory or multi-organ failure [60-63].

The CDC 'Interim guidance on the use of antiviral agents for treatment of human infections with avian influenza $\mathrm{A}(\mathrm{H} 7 \mathrm{~N} 9)$ virus' recommends that all hospitalized patients and all probable and confirmed outpatient cases receive antiviral therapy treatment immediately [58]. The CDC recommends that outpatient cases who have had recent contact with a confirmed H7N9 case should also receive antiviral treatment; however, individuals who only meet criteria for an $\mathrm{H} 7 \mathrm{~N} 9$ travel exposure, are not recommended to receive antivirals. The WHO does not recommend post-exposure chemoprophylaxis with antiviral medications for individuals who have had close contact with individuals confirmed to have $\mathrm{H} 7 \mathrm{~N} 9$ unless the exposed individual is at higher risk for complications from H7N9 infection [64].

\section{Vaccines}

As of late May 2014, eight candidate vaccine viruses for avian influenza $\mathrm{A}(\mathrm{H} 7 \mathrm{~N} 9)$ have passed relevant safety testing and two-way haemagglutination tests [27]. The candidate vaccine viruses are derived from two parent strains: the A/Shanghai/2/2013-like virus and the A/Anhui/1/2013-like virus [27]. Although increased heterogeneity of gene sequences did increase in the third H7N9 wave, the majority of the H7N9 strains that have been characterized to date are antigenically similar to the A/Anhui/1/2013-like candidate vaccine strain and no new candidate vaccine viruses have yet been proposed in 2015 [31, 65].

\section{Exposure and environmental considerations}

H7N9 reservoirs and human exposure

Wild birds are considered the natural reservoir for avian influenza viruses [15]. The H7N9 virus isolated from the 2013 outbreak in China contains genes solely of avian origin [40]. It is a triple reassortant $\mathrm{H} 7 \mathrm{~N} 9$ virus that is 
believed to be the result of a two-step reassortment [5, 40]. Prior to 2013, influenza A(H7N9) had been reported in birds $[14,17]$, but not in humans. Reports of the H7N9 avian virus in wild birds have emerged from ten countries, including China, the Czech Republic, Egypt, Guatemala, Japan, Mongolia, South Korea, Spain, Sweden, and the United States [66, 67]. The virus has been found in domestic poultry in China, Taiwan, and the United States [66].

Human H7N9 cases have consistently been associated with exposure to birds, poultry, or live animal markets, with some exceptions [31, 68, 69]. The virus has been isolated from pigeons, chicken, geese, and ducks [70-72]. A higher risk of H7N9 infection is associated with visiting a market where live poultry is sold, direct contact with poultry or birds in the market, buying poultry or other birds in a live poultry market (LPM) that have been freshly slaughtered, and direct contact during preparation or cooking of poultry [73].

\section{Environmental considerations}

The H7N9 virus is difficult to control environmentally. The virus has been reported to be able to survive for months in the environment and can circulate in avian species in the absence of any clinical signs in birds [1]. Of epidemiological significance, there is some evidence that H7N9 is becoming enzoonotic in China. Reports of the widespread geographical dissemination of the virus indicate that the virus is likely present across most of China [34]. The H7N9 virus has been isolated from environmental samples taken from LPMs, including contaminated soils and surface water [1]. In one study of 8900 live poultry and environmental samples from 36 retail LPMs, six wholesale LPMs and eight poultry farms, $1.5 \%$ of the samples tested positive for H7N9. The virus was detected from 16 of the 36 retail LPMs and three of the six wholesale LPMs, but the virus was not detected in samples taken from poultry farms [71]. Within poultry markets, the virus is most likely to be detected in environmental samples related to poultry sale and slaughtering compared to samples from poultry holding areas [71].

Climate conditions are believed to be implicated in the spread of H7N9 [74]. A higher risk of human infection is associated with temperatures between $13{ }^{\circ} \mathrm{C}$ and $18{ }^{\circ} \mathrm{C}$; whereas lower temperatures are associated with a decreased risk of infection [74]. Environmental studies of other avian influenza viruses have found that viral persistence can vary under different natural conditions in aquatic environments. The majority of avian influenza viruses are most stable at a $\mathrm{pH}$ of 7.4 $8 \cdot 2$ and temperatures of $<17^{\circ} \mathrm{C}$ [75], but experimental studies have demonstrated that the $\mathrm{H} 7 \mathrm{~N} 9$ virus can remain infectious even after exposure to temperatures up to $65^{\circ} \mathrm{C}$ for $5 \mathrm{~min}$, $\mathrm{pH}$ levels of $\geqslant 3$, and UV light for $20 \mathrm{~min}$ [76]. Heat and UV light have been effective in reducing or eliminating the infectivity of the $\mathrm{H} 7 \mathrm{~N} 9$ virus, but either high temperatures or long exposure times ( $>20 \mathrm{~min}$ ) are required. Viral inactivation by $\mathrm{pH}$ is only effective at very low pH levels $(<2-3)$ [76]. When used at recommended concentrations, chemicals such as ethanol or sodium hypochlorite effectively inactivate the virus in $5 \mathrm{~min}$ [76].

\section{Pandemic potential}

There is significant concern over whether H7N9 could be the next pandemic strain of influenza [46]. Three major factors influence the pandemic potential of an influenza strain [77, 78]:

(1) The virus has the ability to cause disease in humans.

(2) There is little immunity to the virus within the population.

(3) The virus has the capacity for sustained human-to-human transmission.

\section{Ability to cause human disease}

H7N9 is classified as a low pathogenicity avian influenza (LPAI); however, this classification is based on its pathogenicity in poultry rather than its pathogenicity in humans $[9,29]$. H7N9 is less pathogenic in poultry and does not cause apparent disease in the avian population. By contrast, the virus is highly pathogenic in humans. Currently case-fatality rates of $36-39 \%$ have been reported for human H7N9 infections [5, 31].

For avian influenza viruses to cause human infection, genetic changes are typically required to alter host range and tissue tropism [12]. Influenza viruses circulating primarily in avian species have a preference for avian host cell receptors $\left(\alpha_{2,3}\right.$-linked sialic acid receptor types). Effective zoonotic spread of avian influenza viruses from avian species to mammals generally requires a change in the target-cell receptor preference of the virus from $\alpha_{2,3}$-linked sialic acid to $\alpha_{2,6}$-linked sialic acid receptor types [12]. Some animals possess sialic acid receptors with dual specificity, potentially 
playing a role in interspecies transfer of avian influenza viruses by serving as intermediate hosts [12]. In comparison with most avian influenza A viruses, the H7N9 virus exhibits an increased affinity for human $\alpha_{2,6}$-linked sialic acid receptor types while exhibiting decreased affinity for the avian $\alpha_{2,3}$-linked sialic acid receptor types [79]. While the intermediate binding specificity is associated with increased tropism for human cells and adaptation of host range, the virus still remains slightly partial to the avian receptor, and thus does not yet have the binding specificity characteristic of a human pandemic virus [79-82].

The tissue tropism of the H7N9 virus in humans is for epithelial and endothelial cells in multiple organ systems [10]. Ciliated and non-ciliated bronchial epithelial cells as well as alveolar epithelial cells particularly support replication of the H7N9 virus [11, 83]. The virus appears to infect and replicate more readily within the human conducting and lower airway than other avian influenza viruses, including H5N1 [11]. Studies have shown that H7N9 exhibits high growth rates and infection at low doses in guinea pigs [84]. Many human strains of H7N9 contain a E627 K mutation of the polymerase basic 2 protein (PB2), which is associated with increased virulence of H7N9 in mice and other mammals and improved replication of the virus in mammals $[40,85,86]$.

\section{Population immunity}

Serological studies indicate that there is very little immunity to the H7N9 virus in the general population. A retrospective serological study analysed 1544 serum samples collected between January and November 2012 from poultry workers in Shanghai, Zhejiang, Jiangsu, and Anhui provinces in Eastern China [23]. No evidence of antibodies to the H7N9 virus was found. Analysis of serum samples from 126 healthcare workers during the first wave of H7N9 outbreaks in 2013 also failed to find antibodies to the virus [87]. Similarly, an analysis of 500 serum samples in Japan found no antibody reaction to the Anhui/1 strain of the H7N9 virus, indicating a lack of human immunity to the H7N9 virus in that region [88]. One seroprevalence study of 316 poultry workers associated with LPMs did find a low seroprevalence rate of antibody against $\mathrm{H} 7 \mathrm{~N} 9(1 \cdot 6 \%)$ in conjunction with positive H7N9 environmental samples [71].

As observed with other $\mathrm{H} 7$ subtype viruses, which are associated with low titres of anti-H7 antibodies [89], individuals infected with H7N9 often exhibit a weak antibody response to the virus [46, 90]. Analysis of the H7N9 virus indicates that the T cell epitope content of the HA sequences is very low [90]. Additionally, compared to various circulating influenza strains, there is limited conservation of the T cell epitopes with other influenza strains, suggesting little cross-reactivity with $\mathrm{T}$ cells specific to currently circulating influenza strains [90]. The potentially low immunogenicity associated with H7N9 raises concerns about the implications for vaccine development [90]. Two H7 subtype vaccines previously tested in small clinical trials were found to be poorly immunogenic, producing little to no serum antibodies to the $\mathrm{H} 7$ haemagglutinin, even when adults received two doses of the high-dose formulations of the vaccine [29].

\section{Transmission potential}

Human infection with avian influenza A(H7N9) was the first documentation of zoonotic transmission of N9 subtype viruses [40]. Mutations indicate that the virus may infect mammals more easily than other avian influenza viruses [68]. Although there is limited evidence of human-to-human transmission, it has primarily been confined to small family clusters [1, 68]. To date, human-to-human transmission appears to be restricted with no evidence that sustained humanto-human transmission has occurred [91].

Most studies have found that the H7N9 virus can be spread efficiently between ferrets via direct contact, but airborne transmission is less efficient [92-95]; however, one study found efficient respiratory droplet transmission in ferrets with an H7N9 strain isolated from an infected human [96]. Other research studies indicate that in addition to having a low infective dose and exhibiting a high growth rate, the H7N9 virus demonstrates efficient contact transmissibility in guinea pigs [84]. The PB2-627 K mutation associated with increased virulence and viral replication in mammals is also associated with increased transmissibility of the H7N9 virus [46].

Co-infection with circulating influenza viruses suggest the potential for re-assortment [97], which could render the virus highly transmissible between humans. Reassortment between influenza A(H7N9) and other local strains has been reported [34, 98], although it has not been associated with a significant increase in transmission efficiency [99]. Using certain assumptions, one influenza modelling study suggested that if reassortment is certain when co-infection with human seasonal influenza and a novel avian influenza virus 
occurs, then only 600 cases would be required for a $50 \%$ chance of reassortment. If reassortment during co-infection is a rare event, the number of cases would need to be significantly higher to have a chance of seeing a reassortment [100].

Several models have been used to estimate the human transmission reproductive number $\left(R_{0}\right)$ for $\mathrm{H} 7 \mathrm{~N} 9$. One study used extensive data from investigations of households with index cases to estimate $R_{0}=0.08$ [95\% confidence interval (CI) $0 \cdot 05-0 \cdot 13$, which was robust to changes in underlying assumptions [18]. In another study, an inferential transmission model was used to analyse three of the 2013 H7N9 clusters. The study estimated that $13 \%$ of the cases were attributable to human-to-human transmission (95\% CI 1-32) [19]. This model also estimated human-to-human $R_{0}$ in each of the three clusters to be 0.19 (95\% CI $0.01-0.49), 0.29$ (95\% CI $0.03-0.73$ ), and 0.03 (95\% CI $0.00-0.22)$, with sensitivity analyses producing estimates as high as 0.39 $(95 \%$ CI $0 \cdot 02-0 \cdot 90)$ if the primary case onset to secondary case onset was only 3 days [19]. Another study estimated $R$ as 0.1 (95\% CI 0.01-0.49) using a Bayesian estimation model [2]. Another estimated $R_{0}$ as $0 \cdot 28$ (95\% CI $0 \cdot 11-$ 0.45 ), acknowledging that this may be an overestimate due to ascertainment and other biases [101]. By contrast, another modelling study estimated $R_{0}$ to be $0.467(95 \%$ CI $0 \cdot 387-0.654)$ and noted that if the reproductive number was approximately twice their estimated $R_{0}$, it could induce a human outbreak of the H7N9 virus [102]. However, the bulk of evidence from the other studies suggests that the relative increase in $R_{0}$ required to reach the critical $R_{0}=1$ threshold could be substantially more than twofold [2, 101, 102].

These $R_{0}$ estimates are very similar to values estimated for the H5N1 strain, which also generally centre close to $0 \cdot 1$ [20], with confidence ranges spanning up to near 0.4 [21]. However, there is evidence that levels of pre-existing immunity to $\mathrm{H} 5 \mathrm{~N} 1$ in the human population is significantly higher than it is for H7N9 [23, 103], which means that H7N9 could pose a higher risk of larger outbreaks despite a similar $R_{0}$ [20]. By contrast, $R_{0}$ estimates for the 2009 pandemic H1N1 strain were in the range of $1 \cdot 2-1 \cdot 7$ [104-106].

\section{Modelling studies}

In addition to the models developed to estimate human-to-human reproductive numbers, other risk-based prediction models have been used to characterize patterns of dissemination and estimate the risk of $\mathrm{H} 7 \mathrm{~N} 9$ spread, including its pandemic potential [2, 107-111].
Many studies have performed spatial and temporal analyses of human infections with H7N9 to either describe H7N9 case clusters, or to determine associated risk factors [112, 113]. Several H7N9 geographical modeling studies have mapped the spread of the disease along with risk factors in those areas, to develop predictive models of disease spread [107]. Fang et al. used geographical information systems (GIS) spatial analysis to map the distribution of H7N9 cases along with other geographical characteristics to explore regional risk factors that could influence the dynamics of H7N9 spread. They mapped the distribution of the virus in affected counties, plotted epidemic curves for the most affected provinces, and merged this information with county-level data on agro-ecological, environmental, and meteorological factors [107]. They then examined how each factor contributed to the spread, and probabilities of human H7N9 infections were mapped. The model ultimately showed that LPMs, population density, irrigated croplands, built-up land, and humidity and temperature were all potentially significant contributors to the occurrence of H7N9 viral infections in humans [107].

Another study predicted the risk of future H7N9 infections in China and neighbouring countries by evaluating the association between $\mathrm{H} 7 \mathrm{~N} 9$ cases at sentinel hospitals, and agricultural, climatic, and demographic risk factors. The study used cross-sectional data and logistic regression to identify risk factors associated with H7N9 infection and subsequently calculated H7N9 risk across Asia by using GIS to construct predictive maps [114]. The model accurately predicted the spread of the virus into Guangxi region in February 2014. The study further predicts a high risk for spread of the virus to northern Vietnam [114]. A spatial epidemiology study performed by Gilbert et al. used datasets with locations of almost 10000 LPMs in China, combined with maps of environmental correlates, to develop a statistical model that was able to accurately predict H7N9 market infection risk across Asia [115]. The study found that local density of LPMs was the most significant predictor of infection risk in markets.

Other statistical risk assessment models have been generated. One modelling study examined the transmission potential compared to other emerging pathogens [2] designating human H7N9 cases as 'spillover' events from animal to human transmission events. This model did not assess human-to-human transmission events. Provided that H7N9 cases are confined to 
spillover events, the transmission potential of H7N9 remains very minimal, with an $R$ value well below what would be required for sustained transmission [2]; however, the study remarked on the fact that early in the outbreak, $23 \%$ of H7N9 cases did not report prior exposure to animals, highlighting the potential role of environment, aerosols, and contact with human cases in the spread of the disease [2,6]. Two additional studies used models to examine whether closure of bird markets had an impact on the incidence of H7N9 human infections and found that the precautionary measure did appear to be effective [2, $116]$, reducing the mean daily number of infections from between $97 \%$ and $99 \%$ according to one of the models [116]. Similarly, another study assessed the potential for H7N9 transmissibility based on daily exposure time of shoppers, farmers, and live-bird market retailers to poultry. The investigators used the data to propose hypotheses of the role of exposure time in infection incidence within certain risk groups, but they found that exposure time in poultry markets was not sufficient to explain the age and gender distribution of the H7N9 outbreaks [109].

Some studies have developed mathematical models focusing on bird-to-bird and bird-to-human transmission. One study confirmed the effectiveness of closing live bird markets in reducing human infections (as observed in other studies) and also highlighted the psychological influence that media outbreak coverage may have in encouraging fewer visits to live-bird markets [117]. Another study provided an estimate of the bird-to-bird reproduction number of close to 4, suggesting that attempts to prevent the spread of H7N9 in birds would require significant effort, but that the rate of bird-to-human transmissions was low and likely to be reduced by timely bird market closures [118].

\section{Risk assessments to determine pandemic potential}

Two major risk assessment tools have been developed by health agencies in Europe and the United States. A risk assessment framework developed by the European Food Safety Authority uses a prototype spatial epidemiological model, which includes inputs for both virological and epidemiological data [110]. The objective of the framework is to enable assessment of the pandemic potential of new influenza viruses or viral subtypes [110]. This model, known as FLURISK, takes genomic information into account to evaluate the risk that the virus could cross the species barrier [110]. It can utilize information from genome sequencing and assign the virus a score that indicates its risk of jumping the species barrier. For H7N9, genomic information from four strains was input into the model, giving virus scores between $0 \cdot 3$ and $0 \cdot 89$. As virus scores approach 1 , the likelihood of jumping the species barrier increases [110]. The virus score, which represents virus-specific components, can be used with a species-specific component to generate a transmission coefficient. The transmission coefficient can be put into a model that estimates the number of new infections in the human population as a result of contact with the affected (avian) species [110].

Another influenza risk assessment tool, known as IRAT, was developed by scientists at the U.S. Centers for Disease Control and Prevention. It utilizes a standardized set of elements that can be used to evaluate the pandemic potential of pre-pandemic viruses in comparison to one another [111]. The intention is to help officials determine where resources could be most effectively placed based on the pandemic risks of an influenza strain relative to other influenza strains. The ultimate goal of the tool is to assist in identifying appropriate candidate vaccine viruses, and to have a vaccine in place for the prepandemic strain before the virus becomes efficiently transmitted between humans [111]. Two main questions, which together encompass the three major pandemic potential factors discussed above, are critical to the IRAT tool. The first question, 'What is the risk that a virus not currently circulating in the human population has the potential for sustained humanto-human transmission?' is intended to assess the emergence potential of the virus [111]. The second question, 'If the virus were to achieve sustained human-to-human transmission, what is the risk that a virus not currently circulating in the human population has the potential for significant impact on public health?' addresses the potential impact the virus could have in the population if the virus began circulating in humans [111]. In addition to these questions, ten elements were incorporated into the IRAT: (1) the antigenic relatedness of the virus to current vaccines, (2) available options for antivirals and other treatments, (3) disease severity and pathogenesis of the virus, (4) genomic variation of the virus, (5) distribution in the global animal population, (6) human infections, (7) animal infections, (8) immunity of the population to the virus, (9) receptor binding ability of the virus, and (10) transmission of the virus in laboratory animals [111]. For both the emergence and impact 
questions above, each of the ten elements is ranked and weighted in order of importance in addressing the two questions. The final weighted risk scores are useful for comparing the pandemic potential of influenza viruses that are not currently circulating in the human population, but the scores do not give a precise quantification of risk [111].

The IRAT element weights and the corresponding unweighted and weighted risk scores for H7N9 and $\mathrm{H} 5 \mathrm{~N} 1$, as determined by Cox et al. and Trock et al. are shown in Table 2 and Figure 2 [111, 119]. The magnitude of the weight corresponds to its ranking for that element. When evaluating these elements with respect to H7N9 and H5N1, many of the risk scores were similar for both viruses. For example, both H7N9 and $\mathrm{H} 5 \mathrm{~N} 1$ were given risk scores of 8.5 for disease severity $[111,119]$. Other risk scores differed significantly, such as transmission in laboratory animals ( 7 and 3 for $\mathrm{H} 7 \mathrm{~N} 9$ and $\mathrm{H} 5 \mathrm{~N} 1$, respectively). H7N9 received a higher overall IRAT score than H5N1 for both emergence and impact. For non-avian influenza strains, researchers concluded that H7N9 had a higher risk for emergence (question 1) than North American H1N1, but a slightly lower risk of emergence than H3N2. In terms of potential impact (question 2), H7N9 ranked higher than both North American H1N1 and H3N2 [111].

The IRAT uses input from subject matter experts (SMEs) in various areas and fields, including epidemiology, virology, human and veterinary medicine, animal ecology, and risk assessment [111]; however, theoretically, some elements of the IRAT could be objectively scored by non-subject matter experts (non-SMEs) (Table 2). While this may result in the omission of some IRAT elements, it could still be useful in determining risk scores based on the most critical elements. This could enable use of the IRAT tool for assessing the pandemic potential of an influenza virus relative to itself by longitudinally comparing IRAT risk scores at different points in time. Scientists, policy makers, and health and government officials could potentially use the tool to identify changes in the IRAT risk score that may indicate that the pandemic potential of the virus is increasing.

Cox et al. clearly define the risk group categorization requirements for four of the ten IRAT elements [111]. Definitions for four of the remaining six elements are proposed here as well as modifications to the risk scoring to adapt the IRAT tool for use by non-SMEs. Risk scores for low, moderate, or high risk, currently corresponding to $0-3,4-7$, and $8-10$, respectively, could be modified to correspond to scores of 1,2 , and 3 , respectively. This would result in less score variation between assessments, but it would simplify the scoring for non-SMEs.

Although the exact definitions for ranking the element of human infection are not provided in the published IRAT tool assessment, SMEs indicated that human infection with the virus is the most critical piece of information for addressing the question of emergence [111]. Information on reported H7N9 human infections and current case counts are readily accessible from the literature and governmental organizations such as the WHO and the Hong Kong Department of Health Centre for Health Promotion [3, 120]. Information on suspected transmission clusters or larger transmission events is usually documented in the peer-reviewed literature. The risk groups for the human infection IRAT element could be defined as follows - low risk: no evidence of human infection; moderate risk: reports of human infection, but sustained human-to-human transmission has not been documented; high risk: reports of sustained human-to-human transmission.

Population immunity is also a critical element for determining the potential impact of an influenza virus on a population. Cox et al. define the population immunity risk groups as follows [111]-low risk: 'evidence of cross-reactive antibodies in at least 30\% of the population in all age groups except for children $\leqslant 17$ years of age'; moderate risk: 'evidence of crossreactive antibodies in at least $30 \%$ of the population only among persons $\geqslant 50$ years of age'; and high risk: ' $\leqslant 10 \%$ of all age groups having evidence of cross-reactive antibodies'. While the risk groups for this element are clearly defined and could be objectively scored, population-based serological studies may be limited or may not provide information on antibody cross-reactivity by age group.

For determining infection in animal species, a low risk is defined as sustained transmission in wild species [114]. Moderate risk is associated with minor outbreaks or sporadic cases of disease in poultry or mammals, cases of infection in mammals with minimal human exposure, or sustained transmission in a few host species. Endemicity in an animal species, particularly in species with close human contact, and sustained transmission in multiple host species are classified as high risk. In general, this information could be objectively identified in the peer-reviewed literature, although geographic variation may need to be considered.

Global distribution in animals could be objectively determined by defining the risk groups as follows - low 
Table 2. IRAT Tool elements and weights as described by Cox et al. [111], potential for assessment by non-subject matter experts, and IRAT scores of H7N9 and H5N1 as determined by the original IRAT tool

\begin{tabular}{|c|c|c|c|c|c|c|c|c|}
\hline IRAT element & $\begin{array}{l}\text { Emergence } \\
\text { weight }\end{array}$ & $\begin{array}{l}\text { Potential } \\
\text { impact } \\
\text { weight }\end{array}$ & $\begin{array}{l}\text { Information } \\
\text { publicly } \\
\text { available }^{\mathrm{a}}\end{array}$ & $\begin{array}{l}\text { Could be } \\
\text { objectively }_{\text {scored }^{\text {b }}}\end{array}$ & $\begin{array}{l}\text { H7N9 IRAT score } \\
\left(\text { score } \times \text { weight }^{c}\right) \\
\text { Emergence }\end{array}$ & $\begin{array}{l}\text { H5N1 }{ }^{d} \text { IRAT score } \\
\left(\text { score } \times \text { weight }^{c}\right) \\
\text { Emergence }\end{array}$ & $\begin{array}{l}\text { H7N9 IRAT } \\
\text { score }(\text { score } \times \\
\left.\text { weight }^{c}\right) \text { Impact }\end{array}$ & $\begin{array}{l}\text { H5N } 1^{\mathrm{d}} \text { IRAT } \\
\text { score }(\text { score } \times \\
\text { weight }^{\mathrm{c}} \text { ) Impact }\end{array}$ \\
\hline Human $^{\mathrm{e}}$ infections & $0 \cdot 2929$ & $0 \cdot 1429$ & $x$ & $x$ & $5(1 \cdot 465)$ & $5 \cdot 67(1.66)$ & $5(0 \cdot 715)$ & $5 \cdot 67(0 \cdot 81)$ \\
\hline $\begin{array}{l}\text { Transmission in } \\
\text { laboratory } \\
\text { animals }\end{array}$ & $0 \cdot 1929$ & $0 \cdot 0336$ & $x$ & $x$ & $7(1 \cdot 350)$ & $3(0 \cdot 58)$ & $7(0 \cdot 235)$ & $3(0 \cdot 1)$ \\
\hline$\underline{\text { Receptor binding }}^{\mathrm{g}}$ & $0 \cdot 1429$ & $0 \cdot 0646$ & $x$ & $x$ & $6 \cdot 3(0 \cdot 9)$ & $3 \cdot 3(0 \cdot 47)$ & $6 \cdot 3(0 \cdot 407)$ & $3 \cdot 3(0 \cdot 21)$ \\
\hline $\begin{array}{c}\text { Population } \\
\text { immunity }\end{array}$ & $0 \cdot 1096$ & $0 \cdot 1929$ & $x$ & $x$ & $9(0.986)$ & $8.67(0.95)$ & $9(1 \cdot 736)$ & $8.67(1.67)$ \\
\hline $\begin{array}{l}\text { Infections in } \\
\text { animals }\end{array}$ & $0 \cdot 0846$ & $0 \cdot 001$ & $x$ & $x$ & $4 \cdot 7(0 \cdot 398)$ & $7 \cdot 25(0 \cdot 61)$ & $4 \cdot 7(0.005)$ & $7 \cdot 25(0 \cdot 01)$ \\
\hline$\frac{\text { Viral genomic }}{\text { variation }}$ & 0.0646 & $0 \cdot 0479$ & & & $8 \cdot 6(0 \cdot 556)$ & $4(0 \cdot 26)$ & $8 \cdot 6(0 \cdot 412)$ & $4(0 \cdot 19)$ \\
\hline$\frac{\overline{\text { Antigenic }}}{\text { relatedness to }}$ & $0 \cdot 0479$ & $0 \cdot 0846$ & & & $3 \cdot 7(0 \cdot 177)$ & $6(0 \cdot 29)$ & $3 \cdot 7(0 \cdot 313)$ & $6(0 \cdot 51)$ \\
\hline $\begin{array}{l}\text { Global distribution } \\
\text { (animals) }\end{array}$ & $0 \cdot 0336$ & $0 \cdot 0211$ & $\times$ & $\times$ & $4 \cdot 7(0 \cdot 158)$ & $5 \cdot 5(0 \cdot 185)$ & $4 \cdot 7(0.099)$ & $5 \cdot 5(0 \cdot 12)$ \\
\hline Disease severity & $0 \cdot 0211$ & $0 \cdot 2929$ & $x$ & $x$ & $8 \cdot 5(0 \cdot 179)$ & $8 \cdot 5(0 \cdot 179)$ & $8 \cdot 5(2 \cdot 49)$ & $8 \cdot 5(2 \cdot 49)$ \\
\hline $\begin{array}{l}\text { Antiviral and } \\
\text { treatment options }\end{array}$ & $0 \cdot 001$ & $0 \cdot 1096$ & $x$ & $x$ & $5 \cdot 8(0.006)$ & $4 \cdot 5(0 \cdot 0045)$ & $5 \cdot 8(0.636)$ & $4.5(0.49)$ \\
\hline $\begin{array}{l}\text { Total IRAT risk } \\
\text { score }\end{array}$ & - & - & - & - & $6 \cdot 18$ & $5 \cdot 18$ & $7 \cdot 05$ & $6 \cdot 60$ \\
\hline
\end{tabular}

${ }^{a}$ Information, when reported, may be located in peer-reviewed literature or government websites.

${ }^{\mathrm{b}}$ Objective using the risk score definitions proposed here.

${ }^{\mathrm{c}}$ As reported by Trock et al. [119] and Cox et al. [111].

${ }^{\mathrm{d}}$ Clade 1.

${ }^{\mathrm{e}}$ Elements in bold font are characteristics of the virus directly related to humans.

${ }^{\mathrm{f}}$ Elements in italics are characteristics of the virus directly related to animals.

${ }^{\mathrm{g}}$ Elements that are underlined are general characteristics of the virus. 


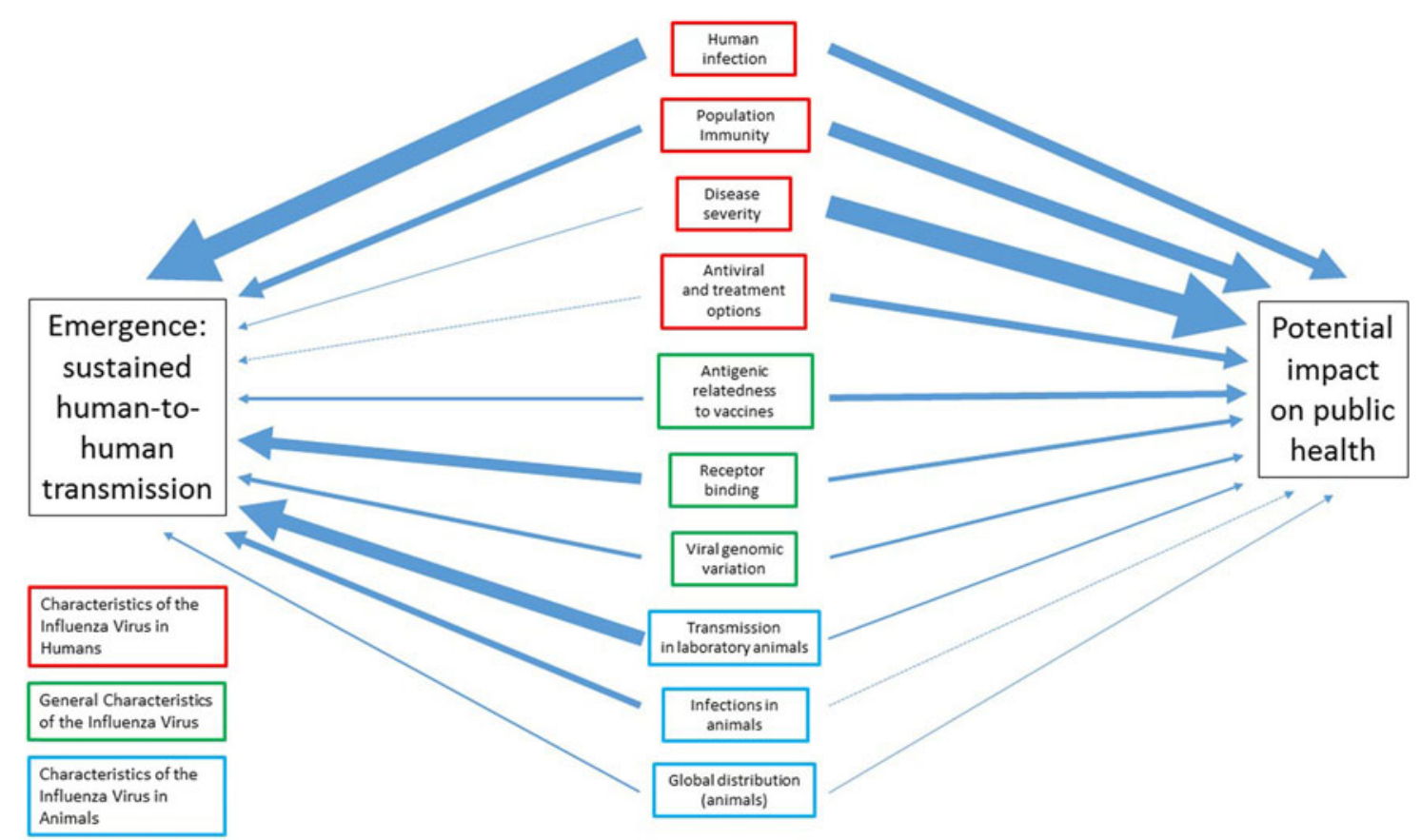

Fig. 2. Relative weights of each IRAT element as they relate to pandemic influenza emergence (sustained human-to-human transmission) and the potential impact on public health, in the case of an outbreak. Based on IRAT weights in Cox et al. [111]. Arrow thickness is proportional to the contributive weight of the IRAT element to pandemic influenza virus emergence or public health impact.

risk: infection in animal species has been reported in a single country; moderate risk: infection in animal species has been reported in multiple countries, but within a single continent; high risk: infection in animal species has been reported on multiple continents.

The objectivity in scoring the disease severity element would depend on the criteria used. If mortality data were used to assign the virus to a risk category, this element could be more objectively scored. However, if the degree of clinical virulence is used to determine this score, then the objectivity could be limited. Cox et al. reported disease severity risk scores for three different influenza viruses: North American $\mathrm{H} 1 \mathrm{~N} 1, \mathrm{H} 3 \mathrm{~N} 2$, and H7N9. These viruses were classified as low risk, moderate risk, and high risk, respectively [111]. Based on reports, the case-fatality rate for North American H1N1 (2009) was estimated to be $<0 \cdot 02 \%$ [121]. By contrast, small studies have reported $\mathrm{H} 3 \mathrm{~N} 2$ case -fatality rates from between $6 \cdot 3 \%$ and $7 \cdot 5 \%[122,123]$, and the current $\mathrm{H} 7 \mathrm{~N} 9$ casefatality rate is between $36 \%$ and $39 \%$ [5, 31]. Based on this data, the risk categories could be defined using a mortality rate range for each risk group.

Two of the elements, viral genomic variation and antigenic relatedness to vaccines, are difficult to classify without some subject matter expertise. These data may also be somewhat limited to the general public. While these elements both have relatively low weights for both emergence and impact as compared to other elements [111], a high risk designation could have some influence on the final score, and misclassification of a low risk virus as high risk could vary the final risk score by as much as a 0.1692 (antigenic relatedness to vaccines, lowrisk group: 0.0846 vs. high-risk group: 0.2538). Because sensitivity of the overall score change is very important, this misclassification could mask a change in risk group for more important elements for each question. As such, it may be preferable to leave these elements out of an IRAT risk assessment performed by non-SMEs.

\section{Limitations of risk assessment tool}

One limitation of non-SME IRAT assessments is that compared to SMEs, non-SMEs will be less able to assess the inherent uncertainty in the risk score estimates for the IRAT elements. Another limitation of non-SME IRAT assessments is the lack of access to information and data that might be available to an SME [111]. Non-SMEs would also likely have more difficulty determining an exact score when larger 
ranges are used for each risk group (e.g. 1-3, 4-7, $8-10)$. In some cases, ranges within a risk group could be helpful for assigning risk scores of elements with a more continuous change. For example, the risk groups for antiviral and treatment options are defined by Cox et al. as - low risk: no evidence of clinically relevant resistance to any of the antiviral drugs approved for human use (NA inhibitors and M2 blockers); moderate risk: sensitivity to all NA inhibitors, but resistance to M2 blockers; high risk: viruses demonstrating resistance to one or more neuraminidase inhibitor antiviral drugs. However, when there are sporadic reports of antiviral resistance for a virus, it may be difficult to classify it into distinct risk groups. Studies often report resistant isolates as a proportion of several tested isolates, and over time this proportion can change.

Elements of the IRAT tool that are quantitative may be better suited for objective assessment and ranking by non-SMEs. Qualitative elements may be more difficult for non-SMEs to rank and may produce the most variable risk scores, even when the data required to rank the element is widely available. If a wider range of scores were used (e.g. 1-3, 4-7, 810), scoring within a risk group ranking (e.g. low, moderate, high) would be more difficult for a non-SME to determine and may require intra-analyst assessment for consistency. Reduction in the score range for each risk group rank would yield greater consistency between analysts and analyses.

The application of the simplified IRAT tool is for the evaluation of the intra-virus change in the IRAT score rather than inter-virus comparison of scores. As with the IRAT tool as described by Cox et al., the score does not provide an absolute quantification of risk, but can be used in the context of a comparison [111]. Misclassification may have minimal effect if the same misclassifications are used in intra-virus comparisons. Although the IRAT tool was primarily designed to assess viruses not currently circulating in the human population, the simplified tool could also potentially be used for annual assessment of seasonal influenza strain severity.

The IRAT tool provides an excellent means for assessing the relative pandemic risk of different influenza strains. If a standardized set of criteria could be established to enable the objective comparison of a virus to itself at different time periods, the IRAT assessment could also serve as a robust instrument for monitoring the progression of the pandemic potential of influenza viruses, and could be a valuable tool for pandemic preparedness.

\section{Conclusion}

With the emergence of the zoonotic H7N9 virus in China, there have been renewed concerns about the potential for a pandemic to arise from an avian influenza strain. The population's immunological naiveté combined with the ability for $\mathrm{H} 7 \mathrm{~N} 9$ to replicate in mice, ferrets, and non-human primates, and the limited ability of ferrets to transmit the virus via airborne routes, suggests that the influenza $\mathrm{A}(\mathrm{H} 7 \mathrm{~N} 9)$ virus has pandemic potential. However, there are still significant barriers, particularly with respect to transmissibility, that would have to be overcome for an H7N9 pandemic to occur. Nevertheless, the rapid increase in $\mathrm{H} 7 \mathrm{~N} 9$ cases indicate that vigilance is crucial and pandemic preparedness measures should be taken now to minimize public health impact if sustained human-to-human transmission of any zoonotic influenza strain is achieved. Modelling reports have indicated that the H7N9 virus demonstrates elements of risk for pandemic potential and that some risks may be increasing. Assessment tools are available to evaluate changes in influenza viruses that may be useful for indicating whether the pandemic risk of H7N9 is increasing.

\section{Acknowledgements}

A.V.G. was on temporary assignment as a Senior Biomedical Science Advisor, Program on Biosecurity and Biosafety Policy, Office of the Director, National Institutes of Health (October 2014-April 2015). We wish to acknowledge colleagues at the Program on Biosecurity and Biosafety Policy, Office of the Director, National Institutes of Health for their support and guidance (Kelly Fennington, Senior Analyst).

This research received no specific grant from any funding agency, commercial or not-for-profit sectors. The views expressed in this article are those of the authors and do not necessarily reflect the position or policy of the Department of Veterans Affairs, the National Institutes of Health, or the United States government.

\section{Declaration of Interest}

None

\section{References}

1. Gautret P, et al. Emerging viral respiratory tract infections-environmental risk factors and transmission. Lancet Infectious Diseases 2014; 14: 1113-1122. 
2. Chowell G, et al. Transmission potential of influenza A/ H7N9, February to May 2013, China. BMC Medicine 2013; 11: 214.

3. Hong Kong Centre for Health Protection Avian influenza report volume 11 number 19 (http://www. chp.gov.hk/files/pdf/2015_avian_influenza_report_vol11 _wk19.pdf). Accessed 12 May 2015.

4. Beigel JH, et al. Avian influenza A (H5N1) infection in humans. New England Journal of Medicine 2005; 353: 1374-1385.

5. Husain M. Avian influenza A (H7N9) virus infection in humans: epidemiology, evolution, and pathogenesis. Infection, Genetics and Evolution 2014; 28: 304-312.

6. Li Q, et al. Epidemiology of human infections with avian influenza $\mathrm{A}(\mathrm{H} 7 \mathrm{~N} 9)$ virus in China. New England Journal of Medicine 2014; 370: 520-532.

7. Kaplan BS, Webby RJ. The avian and mammalian host range of highly pathogenic avian $\mathrm{H} 5 \mathrm{~N} 1$ influenza. Virus Research 2013; 178: 3-11.

8. Yuan R, et al. Pathogenicity and transmission of H5N1 avian influenza viruses in different birds. Veterinary Microbiology 2014; 168: 50-59.

9. USDepartment of Agriculture. Guidelines for avian influenza viruses. 4 November 2011 (http://www.selectagents.gov/ resources/Guidelines_for_Avian_Influenza_Viruses_201111-4.pdf). Accessed 15 January 2015.

10. Belser JA, et al. Pathogenesis, transmissibility, and ocular tropism of a highly pathogenic avian influenza A (H7N3) virus associated with human conjunctivitis. Journal of Virology 2013; 87: 5746-5754.

11. Chan MC, et al. Tropism and innate host responses of a novel avian influenza A H7N9 virus: an analysis of ex-vivo and in-vitro cultures of the human respiratory tract. Lancet Respiratory Medicine 2013; 1: 534-542.

12. Webster RG, Govorkova EA. Continuing challenges in influenza. Annals of the New York Academy of Sciences 2014; 1323: 115-139.

13. Hurt AC, et al. Assessing the development of oseltamivir and zanamivir resistance in $\mathrm{A}(\mathrm{H} 5 \mathrm{~N} 1)$ influenza viruses using a ferret model. Antiviral Research 2010; 87: 361-366.

14. Bertran K, et al. Pathogenesis and transmissibility of highly (H7N1) and low (H7N9) pathogenic avian influenza virus infection in red-legged partridge (Alectoris rufa). Veterinary Research 2011; 42: 24.

15. Brown JD, Poulson R, Stallknecht DE. Wild bird surveillance for avian influenza virus. Methods in Molecular Biology 2014; 1161: 69-81.

16. Fournie G, et al. Identifying live bird markets with the potential to act as reservoirs of avian influenza A (H5N1) virus: a survey in northern Viet Nam and Cambodia. PLoS ONE 2012; 7: e37986.

17. Pérez-Ramírez E, et al. Detection of low pathogenic avian influenza viruses in wild birds in Castilla-La Mancha (south central Spain). Veterinary Microbiology 2010; 146: 200-208.

18. Yang $\mathbf{Y}$, et al. Household transmissibility of avian influenza A (H7N9) virus, China, February to May 2013 and October 2013 to March 2014. Eurosurveillance 2015; 20: pii=21056.
19. Kucharski A, et al. Distinguishing between reservoir exposure and human-to-human transmission for emerging pathogens using case onset data. PLoS Currents 2014; 6: pii.

20. Kucharski AJ, Edmunds WJ. Characterizing the transmission potential of zoonotic infections from minor outbreaks. PLoS Computational Biology 2015; 11: e1004154.

21. Aditama TY, et al. Avian influenza H5N1 transmission in households, Indonesia. PLoS ONE 2012; 7: e29971.

22. Ahmed MS, et al. Cross-reactive immunity against influenza viruses in children and adults following 2009 pandemic H1N1 infection. Antiviral Research 2015; 114 106-112.

23. Bai T, Zhou J, Shu Y. Serologic study for influenza A (H7N9) among high-risk groups in China. New England Journal of Medicine 2013; 368: 2339-2340.

24. Xiong C, et al. Serological study of antibodies to influenza A viruses among general population in Wuhan city China. Journal of Clinical Virology 2014; 61: $178-179$.

25. Lazarus R, Lim PL. Avian influenza: recent epidemiology, travel-related risk, and management. Current Infectious Disease Reports 2014; 17: 1-9.

26. World Health Organization. Cumulative number of confirmed human cases for avian influenza $\mathrm{A}(\mathrm{H} 5 \mathrm{~N} 1)$ reported to WHO, 2003-2015 (http://www.who.int/ influenza/human_animal_interface/EN_GIP_20150106 CumulativeNumberH5N1cases.pdf?ua=1). Accessed 14 January 2015.

27. World Health Organization. Summary of status of development and availability of avian influenza A (H7N9) candidate vaccine viruses and potency testing reagents (http://www.who.int/influenza/vaccines/virus/ candidates_reagents/summary_a_h7n9_cvv_20150317. pdf?ua=1). Accessed 19 May 2015.

28. US Food and Drug Administration. FDA approves first adjuvanted vaccine for prevention of $\mathrm{H} 5 \mathrm{~N} 1$ avian influenza. 2013 (http://www.fda.gov/NewsEvents/ Newsroom/PressAnnouncements/ucm376444.htm).

Accessed 16 January, 2015.

29. Centers for Disease Control and Prevention. Interim risk assessment and biosafety level recommendations for working with influenza $\mathrm{A}(\mathrm{H} 7 \mathrm{~N} 9)$ viruses (http://www. cdc.gov/flu/avianflu/h7n9/risk-assessment.htm). Accessed 10 January 2015.

30. Hong Kong Centre for Health Protection. Avian influenza report (http://www.chp.gov.hk/en/epidemiology/134/332/ 617.html). Accessed 21 May 2015.

31. World Health Organization WHO risk assessment as of 2 October 2014 (http://www.who.int/influenza/human_animal _interface/influenza_h7n9/riskassessment_h7n9_2Oct14. pdf). Accessed 7 January 2015.

32. Hong Kong Centre for Health Protection. Avian influenza report volume 11 number 7 (http://www.chp.gov.hk/ files/pdf/2015_avian_influenza_report_vol11_wk07.pdf). Accessed 20 February 2015.

33. Hong Kong Centre for Health Protection. Avian influenza report volume 11 number 1 (http://www.chp. gov.hk/files/pdf/2015_avian_influenza_report_vol11_wk 01.pdf). Accessed 20 February 2015. 
34. Lam TT, et al. Dissemination, divergence and establishment of H7N9 influenza viruses in China. Nature 2015; 522: 102-105.

35. Liu Y, et al. The third wave: H7N9 endemic reassortant viruses and patient clusters. Journal of Infection in Developing Countries 2015. 9: 122-127.

36. World Health Organization. Influenza at the human-animal interface: summary and assessment as of 31 March 2015 (http://www.who.int/influenza/ human_animal_interface/Influenza_Summary_IRA_HA _interface_31_March_2015.pdf?ua=1). Accessed 15 May 2015.

37. World Health Organization. Antigenic and genetic characteristics of zoonotic influenza viruses and development of candidate vaccine viruses for pandemic preparedness, 2014 (http://www.who.int/influenza/vaccines/virus/20140 9_zoonotic_vaccinevirusupdate.pdf?ua=1). Accessed 8 Jan 2015.

38. Yi L, et al. Family clusters of Avian influenza A H7N9 virus infection in Guangdong province, China. Journal of Clinical Microbiology 2015; 53: 22-28.

39. Xu C, et al. Monitoring avian influenza A(H7N9) virus through national influenza-like illness surveillance, China. Emerging Infectious Diseases 2013; 19: 12891292.

40. Gao R, et al. Human infection with a novel avian-origin influenza A (H7N9) virus. New England Journal of Medicine 2013; 368: 1888-1897.

41. Cowling BJ, et al. Comparative epidemiology of human infections with avian influenza A H7N9 and $\mathrm{H} 5 \mathrm{~N} 1$ viruses in China: a population-based study of laboratory-confirmed cases. Lancet 2013; 382: 129-137.

42. European Centre for Disease Prevention and Control. Human infection with avian influenza A(H7N9) virus fourth update. Rapid Risk Assessment 2015, Stockholm.

43. Wang C, et al. Comparison of patients hospitalized with influenza a subtypes H7N9, H5N1, and 2009 pandemic H1N1. Clinical Infectious Diseases 2014; 58: 1095-1103.

44. Yang Y, et al. Novel avian-origin influenza A (H7N9) in critically ill patients in China. Critical Care Medicine 2014; 43: 339-345.

45. Ji H, et al. Epidemiological and clinical characteristics and risk factors for death of patients with avian influenza a H7N9 virus infection from Jiangsu province, Eastern China. PLoS ONE 2014; 9: e89581

46. Watanabe $\mathrm{T}$, et al. Pandemic potential of avian influenza A (H7N9) viruses. Trends in Microbiology 2014; 22: 623-631.

47. Siston AM, et al. Pandemic 2009 influenza A(H1N1) virus illness among pregnant women in the United States. Journal of the American Medical Association 2010; 303: 1517-1525.

48. Guo Q, et al. Delivery of fetus death with misoprostol in a pregnant woman with $\mathrm{H} 7 \mathrm{~N} 9$ avian influenza A virus pneumonia and ARDS. Critical Care 2014; 18: 589.

49. Qi X, et al. Avian influenza A(H7N9) virus infection in pregnant woman, China, 2013. Emerging Infectious Diseases 2014; 20: 333-334.

50. Qian W, et al. Kinetic analysis of the immunity in a pregnant patient infected with avian influenza H7N9.
International Journal of Clinical and Experimental Medicine 2014; 7: 1768-1774.

51. Hu Y, et al. Association between adverse clinical outcome in human disease caused by novel influenza A H7N9 virus and sustained viral shedding and emergence of antiviral resistance. Lancet 2013; 381: 2273-2279.

52. To KK, Chan JF, Yuen KY. Viral lung infections: epidemiology, virology, clinical features, and management of avian influenza A(H7N9). Current Opinion in Pulmonary medicine 2014; 20: 225-232.

53. Gao HN, et al. Clinical findings in 111 cases of influenza A (H7N9) virus infection. New England Journal of Medicine 2013; 368: 2277-2285.

54. Centers for Disease Control and Prevention Interim guidance on the use of antiviral agents for treatment of human infections with avian influenza A (H7N9) virus (http://www.cdc.gov/flu/avianflu/h7n9-antiviral-treat ment.htm). Accessed 10 January 2015.

55. Hai R, et al. Influenza $A(H 7 N 9)$ virus gains neuraminidase inhibitor resistance without loss of in vivo virulence or transmissibility. Nature Communications 2013; 4: 2854.

56. Liu Q, et al. Emergence of a novel drug resistant H7N9 influenza virus: evidence based clinical potential of a natural IFN-alpha for infection control and treatment. Expert Review of Anti-infective Therapy 2014; 12: 165-169.

57. Sleeman K, et al. R292 K substitution and drug susceptibility of influenza A(H7N9) viruses. Emerging Infectious Diseases 2013; 19: 1521-1524.

58. Furuta Y, et al. Favipiravir (T-705), a novel viral RNA polymerase inhibitor. Antiviral Research 2013; 100: 446- 454.

59. Marjuki H, et al. An investigational antiviral drug, DAS181, effectively inhibits replication of zoonotic influenza A virus subtype H7N9 and protects mice from lethality. Journal of Infectious Diseases 2014; 210: 435-440.

60. Lu S, et al. Analysis of the clinical characteristics and treatment of two patients with avian influenza virus (H7N9). Bioscience Trends 2013; 7: 109-112.

61. To KK, et al. The emergence of influenza A H7N9 in human beings 16 years after influenza A H5N1: a tale of two cities. Lancet Infectious Diseases 2013; 13: 809-821.

62. Wiwanitkit V. H7N9 influenza: The emerging infectious disease. North American Journal of Medical Sciences 2013; 5: 395-398.

63. Xi X, et al. Avian influenza A (H7N9) infections: intensivists as virus hunters in the new century. Journal of Critical Care 2013; 28: 528-530.

64. World Health Organization Avian influenza A(H7N9) virus: post-exposure antiviral chemoprophylaxis of close contacts of a patient with confirmed H7N9 virus infection and/or high risk poultry/environmental exposures (http://www.who.int/influenza/human_animal _interface/influenza_h7n9/13_January_2013_PEP_recs. pdf). Accessed 15 January 2015.

65. World Health Organization Antigenic and genetic characteristics of zoonotic influenza viruses and development 
of candidate vaccine viruses for pandemic preparedness, 26 February, 2015. Accessed 15 May 2015.

66. Abdelwhab EM, Veits J, Mettenleiter TC. Prevalence and control of $\mathrm{H} 7$ avian influenza viruses in birds and humans. Epidemiology and Infection 2014; 142: 896920.

67. Zhao B, et al. Novel avian influenza A(H7N9) virus in tree sparrow, Shanghai, China, 2013. Emerging Infectious Diseases 2014; 20: 850-853.

68. Zambon M. Influenza and other emerging respiratory viruses. Medicine (United Kingdom) 2014; 42: 45-51.

69. Ding H, et al. Epidemiologic characterization of 30 confirmed cases of human infection with avian influenza A(H7N9) virus in Hangzhou, China. BMC Infectious Diseases 2014; 14: 175.

70. Abolnik C. A current review of avian influenza in pigeons and doves (Columbidae). Veterinary Microbiology 2014; 170: 181-196.

71. Chen Z, et al. Detection of avian influenza A(H7N9) virus from live poultry markets in Guangzhou, China: a surveillance report. PLoS ONE 2014; 9: e107266.

72. Wang C, et al. Relationship between domestic and wild birds in live poultry market and a novel human H7N9 virus in China. Journal of Infectious Diseases 2014; 209: $34-37$.

73. Ai J, et al. Case-control study of risk factors for human infection with influenza $\mathrm{A}(\mathrm{H} 7 \mathrm{~N} 9)$ virus in Jiangsu Province, China, 2013. Eurosurveillance 2013; 18: 20510.

74. Zhang Y, et al. The impact of temperature and humidity measures on influenza A (H7N9) outbreaks-evidence from China. International Journal of Infectious Diseases 2015; 30: 122-124.

75. Brown JD, et al. Avian influenza virus in water: infectivity is dependent on $\mathrm{pH}$, salinity and temperature. Veterinary Microbiology 2009; 136: 20-26.

76. Zou S, et al. Inactivation of the novel avian influenza A (H7N9) virus under physical conditions or chemical agents treatment. Virology Journal 2013; 10: 289.

77. World Health Organization Avian influenza (http:// www.who.int/mediacentre/factsheets/avian_influenza/en/) Accessed 23 February 2015.

78. Belser JA, et al. Influenza A virus transmission: contributing factors and clinical implications. Expert Reviews in Molecular Medicine 2012; 12:e39.

79. Xiong X, McCauley JW, Steinhauer DA. Receptor binding properties of the influenza virus hemagglutinin as a determinant of host range. Current Topics in Microbiology and Immunology 2014; 385: 63-91.

80. Zhou J, et al. Biological features of novel avian influenza A (H7N9) virus. Nature 2013; 499: 500-503.

81. Xiong $\mathbf{X}$, et al. Receptor binding by an H7N9 influenza virus from humans. Nature 2013; 499: 496-499.

82. de Graaf M, Fouchier RA. Role of receptor binding specificity in influenza A virus transmission and pathogenesis. EMBO Journal 2014; 33: 823-841.

83. Knepper J, et al. The novel human influenza A(H7N9) virus is naturally adapted to efficient growth in human lung tissue. mBio 2013; 4: e00601-00613.
84. Gabbard JD, et al. Novel H7N9 influenza virus shows low infectious dose, high growth rate, and efficient contact transmission in the guinea pig model. Journal of Virology 2014; 88: 1502-1512.

85. Bi Y, et al. Assessment of the internal genes of influenza A (H7N9) virus contributing to high pathogenicity in mice. Journal of Virology 2015; 89: 2-13.

86. Jonges M, et al. Emergence of the virulence-associated PB2 E627 K substitution in a fatal human case of highly pathogenic avian influenza virus $\mathrm{A}(\mathrm{H} 7 \mathrm{~N} 7)$ infection as determined by Illumina ultra-deep sequencing. Journal of Virology 2014; 88: 1694-1702.

87. Xu W, et al. Serological investigation of subclinical influenza $\mathrm{A}(\mathrm{H} 7 \mathrm{H} 9)$ infection among healthcare and non-healthcare workers in Zhejiang province, China. Clinical Infectious Diseases 2013; 57: 919-921.

88. Watanabe T, et al. Characterization of H7N9 influenza A viruses isolated from humans. Nature 2013; 501: 551-555.

89. Meijer A, et al. Measurement of antibodies to avian influenza virus $\mathrm{A}(\mathrm{H} 7 \mathrm{~N} 7)$ in humans by hemagglutination inhibition test. Journal of Virological Methods 2006; 132: 113-120.

90. De Groot AS, et al. Low immunogenicity predicted for emerging avian-origin H7N9: implication for influenza vaccine design. Human Vaccines \& Immunotherapeutics 2013; 9: 950-956.

91. Qi X, et al. Probable person to person transmission of novel avian influenza A (H7N9) virus in Eastern China, 2013: epidemiological investigation. British Medical Journal 2013; 347: f4752.

92. Belser JA, et al. Pathogenesis and transmission of avian influenza A (H7N9) virus in ferrets and mice. Nature 2013; 501: 556-559.

93. Zhu H, et al. Infectivity, transmission, and pathology of human-isolated H7N9 influenza virus in ferrets and pigs. Science 2013; 341: 183-186.

94. Richard M, et al. Limited airborne transmission of H7N9 influenza A virus between ferrets. Nature 2013; 501: 560-563.

95. Xu L, et al. Novel avian-origin human influenza A (H7N9) can be transmitted between ferrets via respiratory droplets. Journal of Infectious Diseases 2014; 209: 551-556.

96. Zhang Q, et al. H7N9 influenza viruses are transmissible in ferrets by respiratory droplet. Science 2013; 341: 410-414.

97. Zhu Y, et al. Human co-infection with novel avian influenza A H7N9 and influenza A H3N2 viruses in Jiangsu province, China. Lancet 2013; 381: 2134.

98. Ke C, et al. Circulation of reassortant influenza A (H7N9) viruses in poultry and humans, Guangdong Province, China, 2013. Emerging Infectious Diseases 2014; 20: 2034-2040.

99. Meng Z, et al. Possible pandemic threat from new reassortment of influenza A(H7N9) virus in China. Eurosurveillance 2014; 19: pii=20699.

100. Ferguson NM, et al. Public health. Public health risk from the avian H5N1 influenza epidemic. Science 2004; 304: 968-969. 
101. Nishiura H, Mizumoto K, Ejima K. How to interpret the transmissibility of novel influenza A(H7N9): An analysis of initial epidemiological data of human cases from China. Theoretical Biology and Medical Modelling 2013; 10: 30.

102. Xiao Y, et al. Transmission potential of the novel avian influenza A(H7N9) infection in mainland China. Journal of Theoretical Biology 2014; 352: 1-5.

103. Kucharski AJ, Edmunds WJ. Cross-immunity and age patterns of influenza A(H5N1) infection. Epidemiology and Infection 2015; 143: 1119-1124.

104. Fraser C, et al. Pandemic potential of a strain of influenza A (H1N1): early findings. Science 2009; 324: 1557-1561.

105. Yang Y, et al. The transmissibility and control of pandemic influenza A (H1N1) virus. Science 2009; 326: 729-733.

106. Van Kerkhove MD, et al. Epidemiologic and virologic assessment of the 2009 influenza A (H1N1) pandemic on selected temperate countries in the Southern Hemisphere: Argentina, Australia, Chile, New Zealand and South Africa. Influenza and Other Respiratory Viruses 2011; 5: e487-e498.

107. Fang LQ, et al. Mapping spread and risk of avian influenza A (H7N9) in China. Scientific Reports 2013; 3: 2722.

108. Shi B, et al. Inferring the potential risks of H7N9 infection by spatiotemporally characterizing bird migration and poultry distribution in eastern China. Infectious Diseases of Poverty 2013; 2: 8.

109. Rivers C, et al. Estimating human cases of avian influenza A(H7N9) from poultry exposure. PLoS Currents 2013; 5: pii.

110. De Nardi M, et al. Development of a risk assessment methodological framework for potentially pandemic influenza strains (FLURISK). European Food Safety Authority, 2013; EFSA supporting publication 2014: EN-571.

111. Cox NJ, Trock SC, Burke SA. Pandemic preparedness and the Influenza Risk Assessment Tool (IRAT). Current Topics in Microbiology and Immunology 2014; 385: 119-136.

112. Liu W, et al. Spatial and temporal analysis of human infection with avian influenza $\mathrm{A}(\mathrm{H} 7 \mathrm{~N} 9)$ virus in China, 2013. Eurosurveillance 2013; 18: pii: 20640.
113. Qiu J, et al. Spatiotemporal pattern and risk factors of the reported novel avian-origin influenza A(H7N9) cases in China. Preventive Veterinary Medicine 2014; 115: 229-237.

114. Fuller T, et al. Identifying areas with a high risk of human infection with the avian influenza A (H7N9) virus in East Asia. Journal of Infection 2014; 69: 174-181.

115. Gilbert M, et al. Predicting the risk of avian influenza A H7N9 infection in live-poultry markets across Asia. Nature Communications 2014; 5: 4116.

116. Yu H, et al. Effect of closure of live poultry markets on poultry-to-person transmission of avian influenza A H7N9 virus: an ecological study. Lancet 2014; 383: 541-548.

117. Liu S, et al. Global dynamics of avian influenza epidemic models with psychological effect. Computational and Mathematical Methods in Medicine 2015; 2015: 1-12.

118. Hsieh YH, et al. Quantification of bird-to-bird and bird-to-human infections during 2013 novel H7N9 avian influenza outbreak in China. PLoS ONE 2014; 9: e111834.

119. Trock S, et al. Development of an Influenza Risk Assessment Tool, 2012 (http://www.usaha.org/Portals/6/ Committees/foreign-emerging/presentations2012/TrockFluRiskAssessmentTool-FED2012.pdf). Accessed 20 May 2015.

120. World Health Organization. WHO risk assessment as of 23 February 2015 (http://www.who.int/influenza/ human_animal_interface/influenza_h7n9/RiskAssessment _H7N9_23Feb20115.pdf?ua=1). Accessed 24 March 2015.

121. Van Kerkhove MD, et al. Estimating age-specific cumulative incidence for the 2009 influenza pandemic: a meta-analysis of $\mathrm{A}(\mathrm{H} 1 \mathrm{~N} 1)$ pdm09 serological studies from 19 countries. Influenza and Other Respiratory Viruses 2013; 7: 872-886.

122. Eibach D, et al. Routes of transmission during a nosocomial influenza $\mathrm{A}(\mathrm{H} 3 \mathrm{~N} 2)$ outbreak among geriatric patients and healthcare workers. Journal of Hospital Infection 2014; 86: 188-193.

123. Lo YC, et al. Surveillance and vaccine effectiveness of an influenza epidemic predominated by vaccinemismatched influenza B/Yamagata-lineage viruses in Taiwan, 2011-12 season. PLoS ONE 2013; 8: e58222. 